\title{
Risky Information: Social Limits to Risk Management
}

\section{Peter Mascini*}

This article demonstrates that systematic biases occur in (near-)accident reporting. This conclusion is based on a quantitative document analysis of 208 reports recently written by employees of an industrial company. The effectiveness of accident reporting, as an instrument for risk management, is hampered because employees take the relationship with their colleagues into account when reporting. The way of reporting proves to vary with the horizontal and vertical relational distance of the reporting employee to the person who is held responsible for the reported event. These findings support the Normal Accident Theory and weaken the empirical basis of the High Reliability Theory.

(...) an effort to impose a formal rationale on the collection and composition of information has the character of a vacuous exercise because the expressions which the so-ordered documents will contain will have to be 'decoded' to discover their real meaning in the light of the interest and interpretation which prevails at the time of their use (Garfinkel, 1967: 206).

\section{Introduction}

In the first chapter of his study The Limits of Safety, Sagan (1993) contrasted the High Reliability Organization Theory (HRT) with the Normal Accident Theory (NAT) as the most important schools of thought in Organization Theory related to safety and reliability of complex technological systems. The broadest underlying proposition in the HRT is that organizations which meet certain conditions are, in principle, able to manage risks effectively. According to the NAT, the possibilities for controlling technological risks are limited because of economic, cultural and technologicalsystem characteristics. One of the most important conditions put forward by HRT for the management of risks is that of the "culture of reliability'. In such a culture, both management and employees subordinate all other organizational goals to safety. According to the NAT, there will always be situations in which it is not at all clear to employees which goals should be pursued or at which point they should subordinate risk management to conflicting formal or informal goals.

In the special issue of this journal, entitled 'Systems, Organizations and the Limits of Safety: A Symposium', it was debated, rigorously, whether Sagan had formulated (the nuances of) the HRT correctly (La Porte, 1994; La Porte and Rochlin, 1994; Perrow, 1994; Sagan, 1994). Still, this does not lessen the importance of the question, to what extent employees try to realize goals that are opposed to the management of technological risks. This question also underlies this research on the effectiveness of (near-) accident reporting. The purpose of accident reporting is to gather information about the causes of events that deviate from how production processes 'ought to be' (Turner, 1994: 31). The goal of this article is to answer the question to what extent the pursuing of goals other than risk management lead employees to biased reporting about unforseen events. In order to answer this question, reports were used which had recently been written by employees in a large factory (with over 250 employees ${ }^{1}$ ). In the first section of this factory, raw materials are converted into a source of energy; in the second, basic chemicals are produced.

\section{Theory and Hypotheses: The Social Aspects of Accident Reporting}

In order for accident reporting to be effective, causes of deviating events need to be exposed. However, Groeneweg (1992: 103-118) showed that reporters single-out different causes based on information about accidents. This leads to the supposition that reporters render deviating events in accordance with their perception of reality. This would mean that reports are not reliable, in that they contain different, possibly conflicting, interpretations about the same event (March, Sproul and Tamuz, 1991: 3).

One of the reports examined confirms this
*Erasmus University, Department of Sociology, PO Box 1738, 3000 DR Rotterdam, The Netherlands 
pre-supposition. It concerns an accident which led to an injury. One supervisor wrote about this accident: "The person involved was rummaging through the scrap box, whereby he cut himself on a shard of glass which was lying in this box. ${ }^{2}$ He points out that there was 'limited light' and argued that the victim is blameless because "the victim] did not expect that there would be glass in the box.' However, the account of a higherranking employee sheds a totally different light on this event. This person writes: 'searching through scrap boxes is not allowed.' In his view, the 'searching' is the cause of the accident and he views the victim as responsible for the accident. This report shows that the same accident can be judged quite differently by two employees. If reports are, indeed, influenced by the prejudiced, selective perception of reporters, then others can always dispute whether a reporter has stated the 'true' causes of a (near) accident.

Disputes are likely to arise because reports are not only used to learn from deviating events, but also to evaluate employees for actions taken within the realm of their responsibilities (Tamuz, 1987). This accountability is the most important reason why people are inclined to resist judgements about their (co-)responsibility for unwanted events (Bonazzi, 1983; Gephart, 1993; Sinclair and Haines, 1993). This tendency to resist is in line with psychological research demonstrating that people are inclined to attribute their own mistakes to external causes (such as bad luck or freak circumstances), while they attribute other people's mistakes to personal characteristics (such as, negligence or incompetence). The combination of the inherent debatability of reports and the interests involved makes it likely that the determination of responsibilities in accident reporting will be a potential source of conflict.

This can also be deduced from one of the reports studied. In this report, an employee reproaches the workers on another shift for their 'negligence/laziness because, once again, there were no gloves in stock', leading to a situation in which the employees from his own shift ran the risk of getting chemical products on their bare hands. This report was mentioned in an interview as followed: 'This was not appreciated. The reporter was not thanked for it. The shift concerned has made quite some remarks about it. Some people really can make a fuss and when they found out who wrote that report, it certainly did not make him more popular.'

It can, therefore, be expected that reporters will take into account the likelihood of conflicts. Yet another report confirms this expectation. This report closes with the words: 'I hope to have provided you with valuable information and likewise hope that our otherwise good relationship and co-operation will be continued in the same pleasant fashion.' This raises the question of the degree to which reporting is influenced by reporters allowing for possible conflict.

\section{Hypotheses}

Black's (1984) theory of social control provides a rationale for making predictions concerning the accounting for possible conflict. Black (1984: 5) defines social control as '... how people define and respond to deviant behaviour.' In his view, the reaction to deviant behaviour increases with the relational distance between people (1984: 22). The relational distance is '... the degree to which people participate in one another's lives' (Black, 1984: 21). His explanation of the connection is that '... intimacy breeds partisanship' (Black, 1984: 21).

Black's (1984) 'relational distance' hypothesis has been confirmed by several studies. Hembroff (1987) has shown, for example, that the way citizens judge unlawful acts (theft and stabbing someone with a knife) is harsher if the culprit is less, and the victim more, socially integrated. This harshness, likewise, increases with the distance in status position between the two, despite the nature of the law broken. In another study, Wittek (1996) has shown that employees sent out a negative relational signal more often as a reaction to mistakes made by colleagues if they felt less attached to them. In a review article, Plous (1993:41) has cited many psychological studies which show that people are generally '... much more willing to blame dissimilar others than similar others for wrongdoing'.

The hypotheses tested in this research are also based on the 'relational distance' hypothesis. Both the horizontal and the vertical relational distance between employees are determined by the division of labour. The author pre-supposes that, with respect to the horizontal division of labour, the more employees cooperate with the colleagues they report about, the more they will take into account the risk of a conflict. Thus, the more intense the cooperation, the more an employee puts at stake with his judgement. It can be expected that the risk of conflict in relation to the vertical division of labour will depend on the power position reporters take up with respect to the colleague they are reporting on. After all, subordinates have less formal means of power at their disposal than super-ordinates. The more subordinate the position of reporters in relation to the employee they are reporting about, the more they will realise that a conflict is unlikely to be decided in their advantage (Baumgartner, 1984). Two hypotheses, which follow from the above mentioned, are: 
The greater the horizontal distance to the person reported about (Hypothesis 1) and the stronger the power position (Hypothesis 2), the harsher the judgements of employees are about the responsibilities of colleagues in relation to incidents and accidents.

Hypothesis three is based on the premise that employees, to a greater degree, take into account the risk of a conflict, when it is likelier that colleagues will be held to account on the basis of a judgement. This chance increases with the severity of the consequences of the event in the form of material damage, environmental pollution or personal injury. This leads to Hypothesis 3:

If the report has to do with a near-accident, then employees will be harsher in their judgement of the responsibilities of the person reported than when it is about an accident that has actually occurred.

The last two hypotheses deal with the reporter's decision on whether to render a judgement about responsibilities in accident reports. While the first three hypotheses deal with the intention of the judgement, the last two deal with whether a judgement is made at all.

Employees who want to avoid conflicts will try to refrain from making judgements. Again, the prediction is that the more intense the cooperation and the more subordinate the power position, the more effort they will make to avoid judging. It is presumed that the reporter's possibility to withhold judgement is limited by the amount of damage caused by a deviating event (for example, in the form of material damage, environmental pollution or physical injuries). After all, questions regarding the circumstances preceding an event will take on greater urgency in the event of significant damage, than in the event of none (Sagan, 1994). In other words, reporters can only make a deliberate choice not to judge in relation to nearaccidents. This means that the degree of reservation to judge can only be deduced from near-accident reports. The leads to the two hypotheses:

The larger the horizontal distance to the colleague reported about (Hypothesis 4) and the stronger the power position (Hypothesis 5), the more likely employees are to report about responsibilities in relation to near-accidents.

\section{Data Collection and Operationalization Data Collection}

In this research, (near-)accident reports were used from the period January 1990 to December 1995. The factory management made them available for the purpose of this research project. The reports were written by employees at all of the hierarchical and departmental levels. Even contracted personal wrote a number of the reports. The reports dealt with such diverse subjects as exceeding the maximum speed limit on the factory site, a twisted ankle caused by loose pieces of cokes, falling material, leaky pipes and, once, a fatal fall.

Only those documents were included in which reporters blamed or justified actions with respect to a (near-)accident. In 196 cases, reporting employees rendered judgements about one particular employee. In 28 documents, reporters attributed the responsibility to different employees. These reports were split into more cases. This resulted in a total of 224 cases.

\section{Operationalization of the Dependent Variables}

In the case of the first three hypotheses, the dependent variable is the harshness of the judgement of employees about the responsibility of colleagues for the (near-)accident they are reporting about.' This variable is composed of the following four characteristics:

- A (i) strong or (ii) a weak accusation about acts in relation to the (near-)accident, or (iii) a weak or (iv) strong justification.

- A (i) minimal or neutral representation of the consequences of the event or (ii) an exaggerated version.

- The reason given for the (near-)accident is (i) a human-error; (ii) organizational; or (iii) technical failure.

- The measures proposed (i) involved preventing human-errors in the future (sixteen times in combination with a proposal to adapt the organization and/or the technology); (ii) to change the organization (four times in combination with a proposal for a technological change); (iii) to prevent technological errors only (twenty-two times) or to propose no follow-up measures at all (forty-three times). ${ }^{3}$

The degree to which the four characteristics are related is calculated using PRINCALS. This SPSS programme is an alternative to factor or principal components analyses when variables are at the ordinal instead of the interval or ratio level. On the basis of the direction and the ranking of the category quantifications, the factor loadings of the different characteristics on the underlying dimension and the Eigen Value of the underlying dimension, it can be concluded that the four characteristics measure a common aspect (see Table $I$ and 2). The strongest possible judgement (which means the lowest score) is composed of a strong accusation in combination with a dramatic rendition of the 
Table 1: PRINCALS Solution for the Ordinal Variable 'Harshness of ther Judgment' $(N=224)$

\begin{tabular}{|c|c|c|}
\hline & Frequencies & Location on the Dimension* \\
\hline \multicolumn{3}{|l|}{ Justification } \\
\hline I Strong justification & 30 & 1.63 \\
\hline 2 Weak justification & 21 & 1.33 \\
\hline 3 Weak accusation & 81 & -0.16 \\
\hline 4 Strong accusation & 92 & -0.79 \\
\hline \multicolumn{3}{|l|}{ Presentation of Consequences } \\
\hline I Minimizing/neutral & 72 & 0.83 \\
\hline 2 Blowing up & 55 & -0.57 \\
\hline Missings ${ }^{* *}$ & 97 & \\
\hline \multicolumn{3}{|l|}{ Cause } \\
\hline I Technological & 39 & 1.75 \\
\hline 2 Organizational & 32 & 0.35 \\
\hline 3 Human & 153 & -0.58 \\
\hline \multicolumn{3}{|l|}{ Follow-Up Measure } \\
\hline I Technological & 65 & 0.90 \\
\hline 2 Organizational & 64 & 0.28 \\
\hline 3 Human & 95 & -0.90 \\
\hline \multicolumn{3}{|c|}{$\begin{array}{l}{ }^{*} \text { This is the location of the separate categories on the dimension 'harshness of the judgement'. } \\
\text { **The frequency distribution illustrates that the cases with missings ('presentation' has } 97 \text { missings) have also been } \\
\text { incorporated in the calculation. The explanation for this is that the condition to the calculation has been made that the } \\
\text { answer to one of the four variables was allowed to be absent. This was done in order to ensure that none of the cases } \\
\text { in which the valid score on one of the four variables was absent had to be excluded. When one valid score was absent, } \\
\text { PRINCALS estimated the score that was most likely in light of the scores on the other three variables. }\end{array}$} \\
\hline
\end{tabular}

Table 2: PRINCALS Solution for the Factor Loadings $O n$ and the Eigen Value of the Ordinal Variable 'Harshness of the Judgment' $(N=224)$

\begin{tabular}{|lc|}
\hline & $\begin{array}{c}\text { Factor } \\
\text { loadings }\end{array}$ \\
\hline Justification & 0.89 \\
Presentation of consequences & 0.55 \\
Cause & 0.88 \\
Follow-up measures & 0.77 \\
Eigen value dimension & 0.62 \\
\hline
\end{tabular}

consequences of the event, the pointing out of human error as the cause and the proposal to take measures to preclude the re-occurrence of similar human errors.

The dependent variable for the last two hypotheses is 'the decision whether or not to render a judgement about responsibilities in an accident report'. This variable is based on the assumption that reporters can only decide not to render a judgement in cases of near-accident. This means that the judgements in relation to near-accidents are considered to be a variable, while those in relation to accidents are viewed as a constant. The reservation to judge on the part of the reporters can, therefore, be measured by the ratio of the number of judgements about near-accidents and accidents. This means that the fewer the judgements employees render in nearaccident reports, in comparison to the number of judgements given in accident reports, the more often they have used their freedom of choice to withhold a judgement and the more they have exhibited a desire to avoid conflicts with their colleagues.

\section{Operationalization of the Independent Variables}

The independent variables are the Horizontal Distance, the Power Relation between the reporter and the reported and the Consequences of the event. The Horizontal Distance is operationalized by determining whether the reporter and the reported work in the same (1) functional unit; (2) department; or (3) organization. ${ }^{4}$ In the case of the Power Relation, it is done by determining whether an employee is reporting about (1) a subordinate; (2) about a colleague working in the same hierarchical layer; or (3) about someone placed above him hierarchically. With respect to the Consequences, the categories of the determination used were whether the event (1) did or (2) did not leave any clear traces in the form of 
Table 3: Harshness of the Judgement Explained by the Main Effects of the Horizontal Distance, Power Relation and Consequences $(N=194)$

\begin{tabular}{|lcc|}
\hline \multicolumn{1}{|c|}{ Frequency } & $\begin{array}{c}\text { Corrected deviation } \\
\text { of the average }\end{array}$ \\
\hline Horizontal distance & 71 & 0.64 \\
$1 \quad$ Small & 50 & -0.09 \\
$2 \quad$ Medium & 73 & -0.57 \\
$3 \quad$ Large & & $0.48^{* *}$ \\
Eta & & \\
Power relation & 141 & -0.09 \\
$1 \quad$ Downwards & 37 & 0.36 \\
2 Same level & 16 & -0.06 \\
$3 \quad$ Upwards & & $0.16^{*}$ \\
Eta & & -0.18 \\
Consequence & 118 & 0.27 \\
$1 \quad$ None & 76 & $0.20^{* *}$ \\
$2 \quad$ Yes & & $41.5^{* *}$ \\
Eta & & \\
Total amount of explained variance per cent & & \\
\hline${ }^{*} p<0.05 \quad{ }^{* *} p<0.01$ & & \\
\hline
\end{tabular}

material damage, environmental pollution or personal injuries (See Table 3 for the frequencies.)

\section{Results}

The first three hypotheses about the harshness of the judgement were tested on the basis of an analysis of variance (see Table 3). All independent variables had a significant effect on the harshness of the judgement of the reporters. ${ }^{5}$ Moreover, the analysis proved that Hypotheses 1 and 3 could not be rejected. The less-intensively employees worked with the colleagues they were reporting on, the harsher their judgements were. Their judgements were also harsher when there was little likelihood that colleagues would be held to account on the basis of the judgement, because the events did not leave any clear traces.

Hypothesis 2 was only partially confirmed. The prediction was that the stronger the relative hierarchical position of reporters, the harsher their judgement would be. Employees with a stronger hierarchical position than the ones reported about; that is, those reporting about a subordinate, did, in fact, judge more harshly than employees reporting on colleagues who occupied the same hierarchical position. Employees in the weakest possible position were not, however, the mildest judges: in fact, they judged more harshly than when reporting about someone working at the same hierarchical level. There are at least two possible explanations for this result.

The first is, as has been shown in a great deal of research, that, if means of power are unequally distributed, 'the weak' are more inclined to punish 'the strong' than the other way around (Molm, 1997:120). The reason for this is that the strong can also resort to means of power that are less risky than those based on punishment (such as, rewarding and convincing). One example of such a risk is that the actor who is punished will withdraw from the relationship. For subordinates, punishment is often the only manner of exercising influence; this means that this is, generally, not the case of super-ordinates. The fact that subordinates reported on super-ordinates in just sixteen cases seems to be in accordance with this explanation. After all, this could mean that subordinates only blame superordinates when they consider the situation to be very grave. In these situations, they might, perhaps, see no alternative other than accepting the risk of a conflict.

The second possible explanation can be found in the policy of the management of this particular company. The management had implemented a participatory management system in which the equal distribution of power over the different hierarchical layers was emphasized. One of the most important focuses 
in this type of system is the empathetic and listening attitudes of employees. This system is carried-out primarily by the management. It is possible that, as a result, subordinates perceive the risk of a conflict with management to be smaller than when they judge an employee of the same or subordinate hierarchical level.

Correspondence between a foreman and a higher-placed manager about a proposal to change the rule governing the timing of temperature measuring of ovens illustrates the plausibility of this explanation, because it shows that the foreman is much less empathetic than the manager:

How much more conscientious it would have been if you would have given your opinion directly as an answer to my letter and how preferable it would have been if you had informed the process operators about it and made clear why those 10 to 12 hours were so important to you. In my opinion your comments are useless in their tardiness. In line with the new organization, one could say that the whole process has left me with rather primary feelings (emphasis in original).

On behalf of the assistant manager being targeted, another member of the management reacts by stating: 'Your reaction to the manner in which the proposal was treated is quite apt. [...] Hopefully this incident will not have a negative effect on the effective functioning of the workconsult.'

In summary, the harshness of the reporter's judgement depends primarily on the horizontal distance between the reporter and the reported, somewhat less on the possible consequences for the reportee, and, least of all, on the inequality of power between the two. In total, more than forty per cent of the variation of the harshness of the judgements can be explained by these three independent variables.

As was previously mentioned, the last two hypotheses deal with the decision whether or not to report about responsibilities in accident reports. It was predicted that reporters would be more likely to decide to render judgement on these matters the greater the horizontal distance to those reported was and the stronger the relative power position was. The restraint on the part of reporters to judge responsibilities was measured by comparing the per centages of judgements in near-accident reports to those in accident reports (see the Tables 4 and 5). It proves that Hypothesis 4 cannot be rejected. The ratio between the judgements in near-accident and accident reports varies significantly, depending on the horizontal distance. This means that reporters are more likely to report about responsibilities the greater the horizontal distance to the colleague-reportee is.

The power relation does not have the predicted effect on the ratio between the judgements in near-accident and accident reports, which means that Hypothesis 5 must be rejected. The horizontal distance appears to be a threshold for judging the responsibilities of colleagues, while the power relation is not.

Table 4: Ratio Judgements About Events With and Without Consequences by Horizontal Distance in Percentages $(N=219)$

\begin{tabular}{|lccc|}
\hline & $\begin{array}{c}\text { No } \\
\text { consequence }\end{array}$ & Consequence & $\begin{array}{c}\text { Total } \\
\text { (per cent) }\end{array}$ \\
\hline I Small & 39 & 61 & 33 \\
2 Medium & 61 & 39 & 30 \\
3 Large & 86 & 14 & 37 \\
Total (per cent) & 63 & 37 & 100 \\
\hline$\phi=0.41 \quad p<0.001$ & & & \\
\hline
\end{tabular}

Table 5: Ratio Judgements About Events With and Without Consequences by Power Relations in Percentages $(N=194)$

\begin{tabular}{|lccc|}
\hline & $\begin{array}{c}\text { No } \\
\text { consequence }\end{array}$ & Consequences & $\begin{array}{c}\text { Total } \\
\text { (per cent) } \\
\text { Rows }\end{array}$ \\
\hline I Downwards & 58 & 42 & 73 \\
2 Same level & 65 & 35 & 19 \\
$3 \quad$ Upwards & 75 & 25 & 8 \\
Total (per cent) Columns & 61 & 39 & 100 \\
\hline$\phi=0.10 \quad p=$ not significant & & & \\
\hline
\end{tabular}




\section{Discussion}

The question was raised whether distortions occurred in (near-)accident reporting because employees subordinated risk management to other goals. This proved to be the case. Reporters do anticipate the possibility of becoming involved in conflicts with colleagues whom they blame for deviations in the planned production process. This can be deduced from the phenomenon that they are likely to judge less harshly if the reportee will be held to account on the basis of the judgement (which means that the event has caused any significant damage).

The extent to which employees take good labour relations into account proved to depend on the relational distance between the reporters and the reportees. It was shown that reporters more readily report about responsibilities in relation to near-accidents if the co-operation between the reporter and the reported is less intensive. Secondly, the harshness of their judgements increases with the horizontal distance between the two. The third indication of the influence of the relational distance is that reporters holding an unequal power position, relative to the reportee, render harsher judgements than reporters reporting on employees with an equally-strong position.

Distortions, therefore, do occur in accident reporting because reporters make an effort to not disturb the labour relations. It can also be deduced from two other studies that the effectiveness of accident reporting is influenced negatively because reporters are trying to achieve conflicting goals. Tamuz (1987) showed that accident reporting supplied only a limited contribution to risk management because pilots wanted to avoid being held accountable for their actions. Subsequent to the installation of onboard computer registration of deviations, pilots reported significantly more about near-accidents than they had previously done. Moreover, the difference between the number of reports which dealt with deviations which were registered by the computer and those not automatically registered, increased. Both developments can be understood as a consequence of the personal interests of the pilots. The rules stated that pilots could no longer be held responsible once they had reported an incident. Because of the computer, the likelihood that they would be caught breaking the rules increased. Thus, reporting registered deviations became an ever more attractive option. However, this shows that more near-accidents took place than were reported.

Hawkins (1992) made clear that the contribution of reporting to risk management was influenced negatively by inspectors trying to avoid dis-crediting themselves and the organiza- tion for which they worked. He showed that the decision by English labour inspectors to summon companies for rule-breaking, not only depended on the gravity of the offense, but also on the risk of losing a subsequent lawsuit. Because of this, they started a much larger number of lawsuits about concrete, specific violations that had resulted in obvious accidents, than about violations with respect to general health risks that might only become apparent in the long-run. The reason for this was that it was much more difficult to prove the latter, which left judges a greater latitude for different interpretations and, thus, for interpretations differing from those of the inspectors themselves. This finding is important because the labour inspectors themselves thought that the less concrete rule violations with respect to health were much graver than the concrete violations concerning working conditions.

The fact that not only the employees in the factory under study, but even pilots and labour inspectors do not dedicate themselves fully to controlling technological risks, if doing so stands in the way of achieving other (informal) goals, supports the Normal Accident Theory (NAT) and weakens the High Reliability Theory (HRT). In the factory, a great deal of emphasis was placed on reducing the number of accidents and increasing safety, behaviour that is even more prevalent and prominent in the aviation industry (Perrow, 1984). In the case of the labour inspectorate, ensuring safety and proper working conditions is the only formal organizational goal. This means that, even in organizations with a strong safety culture, in which employees of all ranks emphasize the importance of safety, the contribution of accident reporting to risk management is hampered because employees strive to achieve conflicting goals in these reports.

This means that one has to be cautious not to establish the strength of a 'Safety Culture' only on the basis of the extent to which it is commonly agreed upon that safety is of great importance, as this leaves the complex dilemmas that organizational members are confronted with in their daily activities unnoticed. For example, two employees who attach equal importance to safety and good working conditions could report differently because they do not place equal importance on good working relations. Thus, the power of a 'Safety Culture' can only be deduced from the choices employees make in situations in which the goal of risk management is related to other goals. The 'strength' of Safety Cultures can be ranked according to the extent to which other goals are subordinated to the goal of risk management.

It is, however, far from easy to determine, before-hand, which competing goals will play a 
role of importance. It has long been known that the wish for profit and time-gain (for example, not wearing personal protection measures because they demand extra effort) can influence the management of technological risks negatively. Perrow (1984) has shown that a large number of marine accidents are caused by risk management being subordinated to economic considerations. It is perhaps less evident that the goal of good labour relations also exerts such an influence, even though this is not the first study to illustrate this point. Wilthagen (1993) demonstrated that the striving by Dutch labour inspectors to maintain a good working relationship with the companies being checked, obstructed the effective execution of their task. Vaughan (1996) convincingly showed that effective risk management can even be frustrated by a goal that initially appears to conform perfectly. It was the goal of scientificallygrounded technical perfection that was an important cause of the disaster with the space shuttle Challenger. A tele-conference was held the evening prior to this accident because the supplier of the flamed solid rocket booster wanted to halt the launch. One of the most important reasons for NASA personnel to not head this warning was that the arguments brought forward to make this decision were 'insufficiently scientifically' supported. These examples not only illustrate how important it is to identify the conditions under which competing goals stand in the way of risk management, but also raise questions as to the extent to which it is possible to anticipate them.

The findings with respect to accident reporting, offer, at least, two points of departure to prevent other goals from conflicting with risk management. The first is the sanctioning of employees on the basis of accident reporting. Different studies have shown that if reports are used to punish human errors, employees twist or withhold more information than when it is considered a sign of solidarity if one admits to mistakes others can learn from (Pidgeon, 1996). The finding that senders leave out more information the less they trust the receivers of the messages, especially if it will leave the other with a bad impression, is in line with this finding (O'Reilly and Roberts, 1974; O'Reilly, 1978). This is also the main reason why Perrow (1984), Johnston (1996) and Horlick-Jones (1996) advise removing punitive elements from reporting systems to the degree that this is possible. On the other hand, employees who make deliberate mistakes can evade their responsibilities more easily if reports are used less frequently to punish: '[Thus] what is needed is not a no-blame culture (as some advocates of the safety culture have recommended) but one which establishes the boundary between culpable and tolerable mistakes, in a way that the latter category is as inclusive as possible, while at the same time still retaining some degree of responsibility and accountability' (Pidgeon, 1996: 29).

The relationship between reporters and reportees offers the second starting point for preventing distortions in reporting. It has been shown that the extent to which reporters take into account the possibility of conflicts increases, the more closely reporters and reportees work together. This finding is in accordance with the positive connection Vaughan (1990) found between the degree to which controllers are dependent on the regulated and the risk of cooptation. Vaughan (1990: 228) defines cooptation as 'regulators [who] take the point of view of the regulated because they develop sympathy and affinity for them, compromizing the ability both to identify and report violations.' On the basis of this connection, the advice could be given to not let reports be written by anyone but employees who are independent of the reportees. In this same article, however, Vaughan (1990) demonstrates convincingly that this creates other risks. Operational employees are usually the first to be confronted with deviating events. If they have to leave the reporting about these events to employees who are positioned at a greater distance to the production process itself, then, this heightens the risk of deviating events being described incorrectly, too late, or not at all. Therefore, it is not only important to find the right balance between tolerating unintentional mistakes and demanding that deliberate errors be answered for, but also to be sufficiently involved with what happens during the risky production processes while maintaining sufficient distance with respect to the individuals involved in these processes.

Differences in safety cultures, defined as expressions of collectively shared opinions on the priority of safety in comparison to competing (in-)formal goals, is of great importance in relation to the manageability of technological risks. The research on this topic is still in its infancy. In particular, the question of the conditions under which competing goals influence the desire to achieve a high level of risk management is still a field worthy of investigation. With respect to the area of the (unintended) consequences of efforts to strengthen safety cultures, likewise, not very much is known at present (Vaughan, 1996). It is hoped that this study will contribute to answering these questions with respect to accident reporting.

\section{Acknowledgement}

I want to express my gratitude for the valuable comments on earlier drafts of this paper by Peter 
van der Parre, Freek de Meere, Marco Hessels, Bram Steijn, Jan Berting and, especially, Dick Houtman (all members of the Department of Sociology, the Erasmus University of Rotterdam) and the anonymous reviewers of this journal.

\section{Notes}

1. To be able to guarantee the anonymity of the organization studied, as well that of its employees, names have been omitted.

2. All citations are this author's translations of the Dutch reports analysed.

3. The coding of the reports on the four characteristics of the dependent variable was done by the author. The reliability of the coding was tested by three others. For the results of this inter-rater coding test, see Mascini (1996). See the same for a more detailed report of the operationalization of the dependent variable.

4. The horizontal distance was rated in the third category when employees of independent central services, hired and regular personnel reported about each other.

5. It was impossible to calculate interaction effects because of the empty cell 'small horizontal distance' in combination with 'upward reporting'.

\section{References}

Baumgartner, M.P. (1984), 'Social Control from Below', in Black, D. (Ed.), Toward a General Theory of Social Control: Volume 1 - Fundamentals, Academic Press, Inc., Orlando/London, pp. 303345.

Black, D. (1984), 'Social Control as a Dependent Variable', in Black, D. (Ed.), Toward a General Theory of Social Control: Volume 1 - Fundamentals, Academic Press, Inc., Orlando/London, pp. 1-36.

Bonazzi, G. (1983), 'Scapegoating in Complex Organizations: The Results of a Comparative Study of Symbolic Blame-Giving in Italian and French Public Administration', Organization Studies, Volume 4, Number 1, pp. 1-18.

Garfinkel, H. (1967),'Good Organizational Reasons for 'Bad' Clinic Records', in Garfinkel, H. (Ed.), Studies in Ethnomethodology, Polity Press, Cambridge, pp. 186-207.

Gephart, jr. R.P. (1993), 'The Textual Approach: Risk and Blame in Disaster Sensemaking,', Academy of Management Journal, Volume 36, Number 6, December, pp. 1465-1514.

Groeneweg, J. (1992), Controlling the Controllable: The Management of Safety, DSWO Press, Leiden.

Hawkins, K. (1992), 'FATCATS' and the Prosecution in a Regulatory Agency: A Footnote on the Social Construction of Risk', in Short Jr., J.F. and Clarke, L. (Eds.), Organizations, Uncertainties and Risk, Westview Press, Boulder, pp. 275-296.

Hembroff, L.A. (1987), 'The Seriousness of Acts and Social Contexts: A Test of Black's Theory of the Behaviour of Law', American Journal of Sociology, Volume 93, Number 2, September, pp. 322-347.
Horlick-Jones, T. (1996), 'The Problem of Blame', in Hood, C. and Jones, D.K.C. (Eds.), Accident and Design: Contemporary Debates in Risk Management, UCL Press, London, pp. 61-71.

Johnston, A.N. (1996), 'Blame, Punishment and Risk Management' in Hood, C. and Jones, D.K.C. (Eds.), Accident and Design: Contemporary Debates in Risk Management, UCL Press, London, pp. 72-83.

La Porte, T.R. (1994), 'A Strawman Speaks Up: Comments on the Limits of Safety', Journal of Contingencies and Crisis Management, Volume 2, Number 4, December, pp. 207-211.

La Porte, T. R. and G. Rochlin (1994), 'A Re-joinder to Perrow', Journal of Contingencies and Crisis Management, Volume 2, Number 4, December, pp. $221-226$.

March, J.G., Sproull, L.S. and Tamuz, M. (1991), 'Learning from Samples of One or Fewer', Organizational Science, Volume 2, Number 1, February, pp. 1-13.

Mascini, P. (1996), Risicobeheersing Versus Arbeidsverhoudingen? Grenzen aan De effectiviteit van Ongevalsrapporten als Instrument Voor de Beheersing van Technologische Risico's (Risk Management versus Labour Relations? Limits to the Effectiveness of Accident Reporting as an Instrument for the Control of Technological Risks), Congress-paper presented at Zevende Sociaal-Wetenschappelijke Studiedagen, Amsterdam.

Molm, L.D. (1997), 'Risk and Power Use: Constraints on the Use of Coercion in Exchange', American Sociological Review, Volume 62, Number 1, February, pp. 113-133.

O'Reilly, C.A. (1978), 'The Intentional Distortion of Information in Organizational Communication: A Laboratory and Field Investigation', Human Relations, Volume 31, Number 2, pp. 173-193.

O'Reilly, C.A. and Roberts, K. (1974), 'Information Filtrations in Organizations: Three Experiments', Organizational Behaviour and Human Performance, Volume 11, Number 2, April, pp.253-265.

Perrow, C. (1984), Normal Accidents: Living with HighRisk Technologies, Basic Books, New York.

Perrow, C. (1994), 'The Limits of Safety: The Enhancement of a Theory of Accidents', Journal of Contingencies and Crisis Management, Volume 2, Number 4, December, pp. 212-220.

Pidgeon, N. (1996), 'The Limits to Safety? Culture, Politics, Learning and Man-Made Disasters', Journal of Contingencies and Crisis Management, Volume 5, Number 1, March, pp. 1-14.

Plous, S. (1993), 'Psychological Mechanisms in the Human Use of Animals', Journal of Social Issues, Volume 49, Number 1, pp. 11-52.

Sagan, S.D. (1993), The Limits of Safety: Organizations, Accidents and Nuclear Weapons, Princeton University Press, Princeton.

Sagan, S.D. (1994), 'Toward a Political Theory of Organizational Reliability', Journal of Contingencies and Crisis Management, Volume 2, Number 4, December, pp. 228-240.

Sinclair, A. and Haines, F. (1993), 'Deaths in the Workplace and the Dynamics of Response', Journal of Contingencies and Crisis Management, Volume I, Number 3, September, pp.125-137.

Tamuz, M. (1987), 'The Impact of Computer Surveillance on Air Safety Reporting', Columbia 
Journal of World Business, Volume 22, Number 1, Spring, pp. 69-77.

Turner, B.A. (1994), 'Software and Contingency: The Text and Vocabulary of System Failure?', Journal of Contingencies and Crisis Management, Volume 2, Number 1, March, pp. 31-38.

Vaughan, D. (1990), 'Autonomy, Interdependence and Social Control: NASA and the Space Shuttle Challenger', Administrative Science Quarterly, Volume 35, Number 2, March, pp. 225-257.

Vaughan, D. (1996), The Challenger Launch Decision: Risky Technology, Culture and Deviance at NASA,
The University of Chicago Press, Chicago/ London.

Wilthagen, A.C.J.M. (1993), Het overheidstoezicht op de arbeidsomstandigheden: Een onderzoek naar het functioneren van de Arbeidsinspectie (State Regulation of Occupational Safety and Health: A Study of the Function of the Labour Inspectorate), Universiteit van Amsterdam, Amsterdam.

Wittek, R. (1996), Strategies of Informal Social Control in Organizations: A Framing Perspective, CongressPaper presented at Zevende Sociaal-Wetenschappelijke Studiedagen, Amsterdam. 